\title{
Sterile Inflammatory Role of High Mobility Group Box 1 Protein: Biological Functions and Involvement in Disease
}

\author{
Sera Gonelevue ${ }^{a}$ Abhirup Bandyopadhyay ${ }^{b}$ Saumya Bhagat ${ }^{c}$ Md lqbal Alam $^{d}$ \\ Gausal A. Khan ${ }^{\mathrm{C}}$ \\ aDepartment of Physiology, Fiji School of Medicine, CMNHS, Fiji National University, Suva, Fiji; ${ }^{\text {D Murshidabad }}$ \\ Medical College \& Hospital, Berhampore, Murshidabad, India; ' Department of Physiology, Defence Institute of

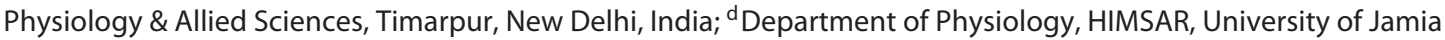 \\ Hamdard, Hamdard Nagar, New Delhi, India
}

\section{Keywords}

High mobility group box 1 protein - Toll-like receptor .

Cardiovascular disease $\cdot$ Stress

\section{Abstract}

High mobility group box 1 protein (HMGB1), a sterile inflammatory molecule and damage-associated molecular pattern (DAMP) released from various cells during stress has been implicated in inflammation. Several reports show that there is a direct relationship between inflammation and cardiovascular diseases (CVDs) such as thrombosis, hypertension, insulin resistance, preeclampsia, etc. Here, we intend to summarize the concept of the emerging link between HMGB1 and CVDs. Furthermore, we will discuss the possible therapeutic strategies that target HMGB1 for the treatment of different CVDs.

(c) 2018 S. Karger AG, Basel

\section{What Are Damage-Associated Molecular Patterns?}

Damage-associated molecular patterns (DAMPs) are endogenous intracellular molecules released in the early phases of nonprogrammed cell death to signal danger

\section{KARGER}

() 2018 S. Karger AG, Basel

E-Mail karger@karger.com

www.karger.com/jvr cues in the early phase of cell injury. These molecules are also called alarmins [1]. Alarmins, include molecules such as high mobility group box 1 protein (HMGB1), adenosine triphosphate (ATP), uric acid, interleukin (IL)- $1 \alpha$, and circulating or cell-free DNA and RNA.

\section{What Is HMGB1?}

HMGB1 is a low-molecular-weight, highly conserved, nonhistone protein $(25 \mathrm{kDa})$ with cytokine-like activity in the extracellular space. It consists of the DNA-binding domains, HMG A-box and HMG B-box in the N-terminus and a continuous stretch of aspartic and glutamic acid-rich negative charge in the C-terminal, respectively. HMGB1 is abundantly and ubiquitously expressed in the nucleus, where it plays a role in DNA replication, transcription, repair, and nucleosome stabilization [2]. It is also found in the cytosol and mitochondria and on the membrane surface, and it can be released to the extracellular milieu via active or passive pathways [3].

Dr. Gausal A. Khan

Department of Physiology, DIPAS, Lucknow Road

Timarpur, New Delhi 110054 (India)

E-Mail gausalk@gmail.com

Abhirup Bandyopadhyay

Murshidabad Medical College \& Hospital, 73 Station Road Gora Bazar, Berhampore, West Bengal 742101 (India)

E-Mail avi9732663682@gmail.com 
The active secretory pathway in immune and nonimmune cells is switched on by the presence of pathogenic products (e.g., bacteria or viruses) or other cell stressors (i.e., cytokines and oxidative stress molecules) [4]. This is a slow pathway because it is mediated through cellular signal transduction [5]. On the other hand, the passive release pathway is fast-acting and occurs in tissue injury and cell death, especially in necrosis and sterile injury events including hypoxia, senescence, and autoimmune disease [6]. After release, HMGB1 accumulates in the extracellular milieu; thereafter, it relays danger signals in the local tissues by triggering inflammatory pathways such as nuclear factor (NF)- $\mathrm{kB}$, extracellular regulated kinase (ERK), p38, CD24, Toll-like receptor (TLR)-2, TLR-4, and TLR-9, the receptor for advanced glycation end-products (RAGE), and others [2]. This results in the activation of innate and adaptive immunity, cytokine, chemokine, and metalloprotease release, and promigration and proinflammatory outcomes $[3,5]$.

HMGB1 has been shown to form complexes with multiple proinflammatory mediators, and thereby enhance their actions in a synergistic manner [7]. Animal models of different disease as well as human studies demonstrate elevated levels of HMGB1 [8]. In vivo experiments also showed HMGB1-induced inflammation while pharmacological intervention on the same molecular target ameliorated sepsis [9]. Over all, these studies suggest that HMGB1 plays a crucial role as a sterile inflammatory mediator for the development of diseases. The different important functions of HMGB1 are presented in detail.

\section{The Role of HMGB1 as a Redox Regulator}

Antoine et al. [10] classified HMGB1 into 3 subtypes according to the amino acid number of cysteine residues in the polypeptide chain: (a) fully reduced or all-thiol HMGB1 (HMGB1C23hC45hC106h), with no disulfide (S-S) bond among the cysteine residues as well as posttranscriptional modification (Fig. 1b); (b) disulfide HMGB1 (HMGb1C23-C45c106h), with an S-S bond between C23 and C45 (Fig. 1c); and (c) sulfonyl HMGB1 (HMGB1C23soC45soC106so) where the sulfate group is oxidized to form sulfonyl by reactive oxygen species (ROS) (Fig. 1d).

Fully reduced HMGB1 may promote leukocyte recruitment by binding to CXCL12 and CXCR4, suggesting that the reduced forms of the 3 cysteine residues contribute to its chemotactic activity $[11,12]$. Platelet-derived HMGB1 has been shown to promote the recruitment of monocytes, and lead to inflammation and thrombosis [13]. Disulfide (or isomerized) HMGB1, characterized by 2 cysteine residues that are oxidized to form an S-S bond between $\mathrm{C} 23$ and $\mathrm{C} 45$, was found to induce NF- $\kappa \mathrm{B}$ translocation and the secretion of inflammatory factors via TLR-4 in activated immune cells, while mutations of C23 or C45 abrogated the cytokine activity of HMGB1 [14]. It also induced bladder pain via TLR-4 [15]. Frank et al. [16] found that it potentiated the neuroinflammatory response in vivo, but that thiol HMGB1 failed to promote the microglial proinflammatory response to lipopolysaccharide (LPS). In line with this observation, a recent study showed that oxidative stress promoted the secretion of HMGB1 and other proinflammatory molecules, where HMGB1 was partially oxidized $[17,18]$. However, in a vein thrombosis model, disulfide HMGB1, released from platelets and neutrophils, influenced neutrophil recruitment and the formation of neutrophil extracellular traps (NETs) that led to thrombosis via TLRs [19]. This suggests that HMGB1 isomerization might contribute to thrombosis through inflammation. The third form of HMGB1 is the sulfonyl or oxidized form which is characterized by 3 fully oxidized cysteine residues. In contrast to fully reduced/all-thiol HMGB1 and disulfide HMGB1, it has currently no known biological function such as chemokine and proinflammatory activities [20].

\section{HMGB1 Signaling for the Initiation of Different Diseases}

HMGB1 fundamentally resides in the nucleus under normal circumstances, stabilizing nucleosomes and facilitating gene transcription [21]. However, under different conditions, it becomes hyperacetylated, translocated from the nucleus to the cytosol, and then secreted actively or passively [22]. It has been shown that HMGB1 passively diffuses from various cells to the extracellular space during cellular necrosis or damage [6]. It is also actively released by macrophages, monocytes, and dendritic cells upon activation [23]. After release from these cells, it exerts its biological functions by interaction with RAGE [24, 25], TLR-2 [26], TLR-4 [27], and TLR-9 [28]. The consequences of these receptor-ligand interactions have been shown to induce cell adhesion [29], permeability [30], chemotaxis [31], inflammation [5], autophagy [32], thrombosis [19], and epithelial-mesenchymal transition [33]. In fact, the exact detailed mechanisms involved in disease progression are still not clear. The mechanism involving myeloid differentiation factor 88 (MyD88)-medi- 


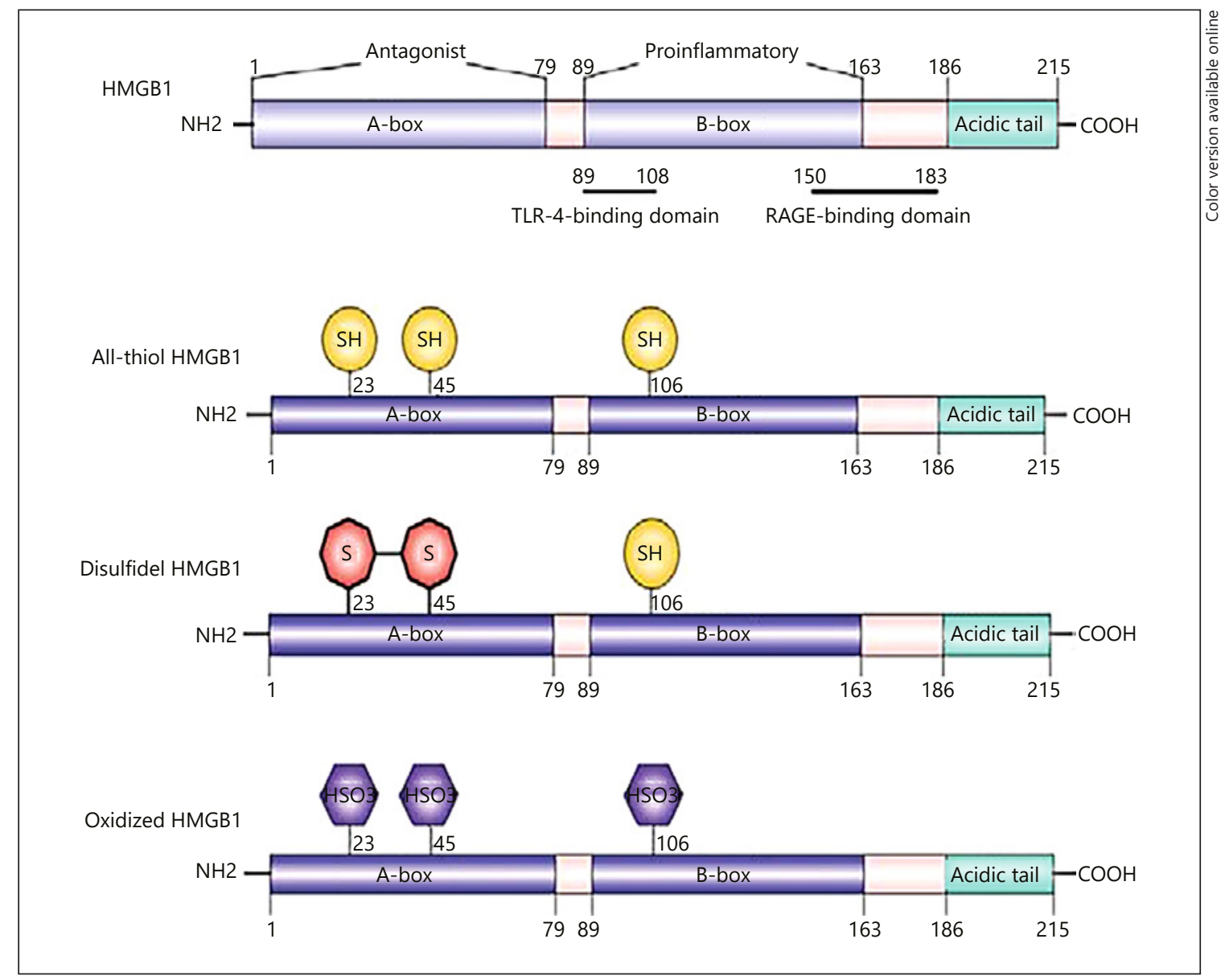

Fig. 1. Structure and redox states of HMGB1. a HMGB1 consists of the A-box (anti-inflammatory domain), Bbox (proinflammatory domain), and the acidic tail. Residues 89-108 were responsible for binding to TLR-4, whereas residues 150-183 were responsible for binding RAGE. b All-thiol HMGB1 exhibited all reduced cystine residues at C23, C45, and C106. c Disulfide HMGB1 was formed by an S-S bond between C23 and C45. d Oxidized HMGB1 is characterized by all 3 oxidized cysteine residues at C23, C45, and C106.

ated pathways have been studied the most. One study showed that the mechanism of HMGB1-induced inflammation is mainly mediated via the MyD88-dependent pathway [34]. MyD88 knockout mice failed to release TNF- $\alpha$ in macrophages as well as IL- 6 in a cold ischemicreperfusion injury model $[35,36]$. HMGB1 promoted antineutrophil cytoplasmic antibody-antigen translocation in neutrophils, which was abrogated by blocking TLR-4, RAGE, MyD88, and NF- $\kappa B$ [37]. Liu-Bryan and Terkeltaub [38] showed that a deficiency of TLR-2 and TLR-4 together, or MyD88 alone, diminished the HMGB1-induced expression of MMP-3 and MMP-13 in chondrocytes. Another study demonstrated that HMGB1 treatment increases the levels of proinflammatory markers in the lungs of wild-type mice but not in TLR-4-/- mice. An in vitro study demonstrated that pharmacological inhibition of TLR-4 or MyD88 also inhibited HMGB1-induced proinflammatory cytokine production [39]. Furthermore, it has been demonstrated that HMGB1 induces proinflammatory cytokine production in vivo via the TLR-4-MyD88-NF- $\kappa B$ pathway [40] (Fig. 2).

\section{HMGB1 and CVDs}

\section{The Role of HMGB1 in Coronary Artery Disease}

It is a well-established fact that HMGB1 has a very important role in the development of CVDs. In this regard, the first line of evidence showed that patients with coronary artery disease (CAD) had significantly higher plasma 


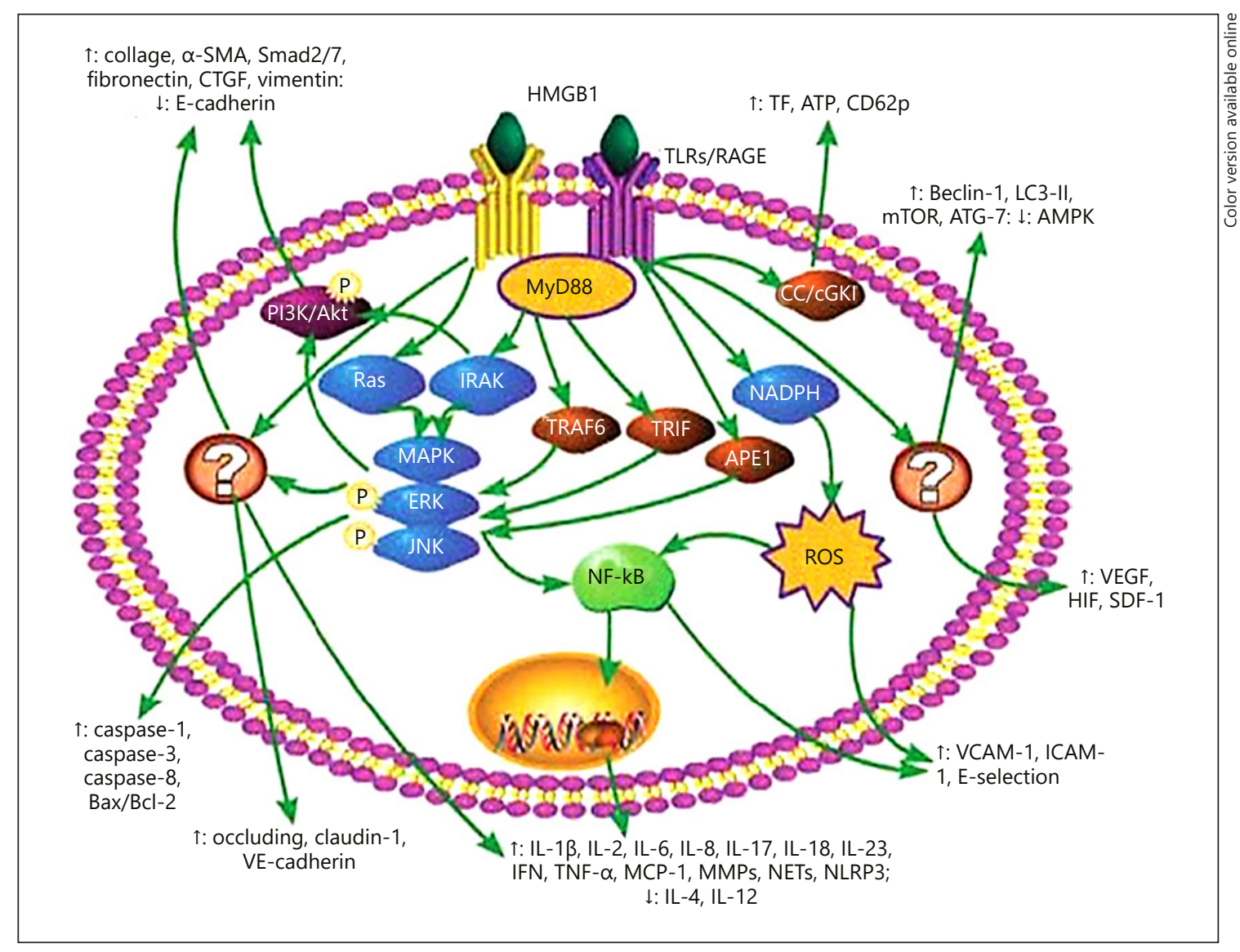

Fig. 2. Signaling pathways of HMGB1. The interaction between HMGB1 and its receptors induced the activation of downstream signaling pathways during cell adhesion, permeability, chemotaxis, inflammation, immunization, autophagy, apoptosis, thrombosis, angiogenesis, fibrosis, and epithelial-mesenchymal transition.

HMGB1 when compared to control subjects [41, 42]. Another study showed that HMGB1 was significantly upregulated in the case of thrombosis (with plaque rupture) when compared with nonthrombotic subjects [43]. However, immunofluorescence data has demonstrated that HMGB1 is abundantly expressed in platelet-rich human coronary artery thrombi [44]. Furthermore, the plasma HMGB1 level in CAD is significantly higher in patients with plaque and chest pain when compared to normal subjects [43]. This suggests that HMGB1 plays a role in the development of atherosclerosis and CAD [45, 46]. Furthermore, ApoE-/- mice exhibited increased expression of HMGB1 in the aortic sinus [25]. Jin et al. [47] showed that the HMGB1 level is higher in patients with myocardial injury and after percutaneous coronary intervention. Therefore, HMGB1 has been considered a potential and independent predictor of cardiovascular mortality in patients with acute coronary syndrome and CAD [48].
The Role of HMGB1 in Stroke

A number of studies have suggested the relationship between HMGB1 and ischemic stroke. Several showed that the plasma HMGB1 level was elevated following ischemic stroke and correlated with the degree of sensitivity $[49,50]$. Elevated HMGB1 is also associated with a poor outcome after ischemic stroke [51]. An animal study (stroke model) delineated that a higher level of HMGB1 is present in the serum [52], plasma [53, 54], and brain tissue of animals with stroke $[55,56]$. Patients with peripheral arterial disease (PAD) had a higher plasma level of HMGB1 when compared to a control group [57]. A higher serum level of HMGB1 was observed in patients with type 2 diabetes mellitus, and this was exaggerated when PAD was also present [58]. HMGB1 level also increases in diabetic foot atherogenesis and influences its clinical outcome [59]. 
The Role of HMGB1 in Disseminated Intravascular Coagulation

Disseminated intravascular coagulation (DIC) is a clinical syndrome characterized by the activation of the coagulation system. Increasing evidence supports the role of HMGB1 in DIC [60, 61]. Serum HMGB1 level was higher in patients with DIC when compared to controls [61]. It is therefore one of the predictive markers for the diagnosis of DIC. Moreover, higher HMGB1 in hematological malignancies might be complicated by the presence of DIC [62]. HMGB1 was also correlated with platelet activation markers in patients with DIC accompanied by hematologic malignancy [63]. However, patients with organ failure and nonsurvivors exhibit the highest HMGB1 levels among patients with DIC [61]. This suggests that elevated HMGB1 is directly associated with organ failure in DIC $[60,61]$.

\section{The Role of HMGB1 in Deep Vein Thrombosis}

Several studies have been reported on the role of HMGB1 in deep vein thrombosis (DVT). The expression of HMGB1 in brain tissue was higher in a cerebral vein sinus thrombosis when compared to the control group [64]. Furthermore, platelet-derived disulfide HMGB1 contributes to vein thrombosis as a central mediator of the sterile inflammatory process [19]. Numerous experimental and clinical studies have shown the role of HMGB1 in thrombosis-related diseases. However, the underlying molecular mechanism is still not clearly understood. We aim to discuss the mechanisms of DVT from 3 aspects: (i) platelet activation; (ii) NET formation; and (iii) fibrinolysis.

Platelets, enucleated cells in the blood, are believed to be centrally involved in thrombus formation. Upon activation, they release several molecules including serotonin, adenosine diphosphate (ADP), von Willebrand factor (vWF), thrombin, and certain growth factors from stored granules. This subsequently promotes platelet activation and aggregation via a positive-feedback mechanism, leading to thrombus formation and thrombosis.

Recently, it has been shown that inflammation also induces thrombosis. HMGB1 has been shown to play an important role in platelet activation and thrombosis [65]. After platelet activation, HMGB1 is translocated from the cytoplasm and onto the membrane surface where it exerts its effects [66]. HMGB1-treated mice also exhibit higher platelet concentrations than controls [67]. The mechanism of action could involve binding on the platelet membrane, which leads to further granular secretion and aggregation [68].
In another study, it was shown that a genetic deficiency of HMGB1(-/-) could increase bleeding time and induce platelet aggregation and thrombus formation [69]. Zhang et al. [70] demonstrated that LPS-activated platelet aggregation was mediated through the TLR-4 pathway. However, deletion of the TLR4 gene resulted in decreased expression of P-selectin in platelets and caused the failure of aggregation in the presence of thrombin [71]. Yang et al. [68] showed that HMGB1/TLR-4-mediated signaling contributes to platelet activation and thrombosis. Another study demonstrated that platelets with genetically deleted HMGB1 (-/-) failed to aggregate [69]. Furthermore, ERK and guanylate cyclase (GC)/cyclic guanosine monophosphate (cGMP)/cGMP-dependent protein kinase I (cGKI) were found to be the downstream signaling pathways of TLR-4 in HMGB1-induced platelet activation and thrombosis [69].

$\mathrm{NF}-\kappa \mathrm{B}$ is the master transcriptional regulator for many genes. HMGB1 signaling has been shown to be mediated via the NF- $\kappa B$ pathway whereas inhibition of NF- $\kappa B$ impairs HMGB1-induced platelet activation and aggregation [68]. This finding suggests that NF- $\kappa \mathrm{B} / \mathrm{I} \kappa \mathrm{B} \alpha$ is involved in HMGB1-induced platelet activation $[68,72]$. Hence, HMGB1-induced platelet activation and aggregation are mediated via the TLR-4/NF- $\kappa \mathrm{B} / \mathrm{I} \kappa \mathrm{B} \alpha / \mathrm{cGMP}$ pathway.

\section{The Role of HMGB1 in the Formation of NETs and} the Development of Thrombosis

Sterile inflammation (SI) is non-pathogen-induced inflammation where stress or environmental factors play a major role. This type of inflammation has been implicated to be the pathophysiological basis of several CVDs like atherosclerosis, thrombosis, myocardial injury, insulin resistance (IR), and many acute conditions [26]. The relationship between HMGB1 and SI was reviewed in 2014 and studies have delineated the involvement of HMGB1 in the SI process [73]. Pharmacological inhibition of HMGB1 abrogates monocyte recruitment, leukocyte activation, and prothrombotic activity [19], suggesting that HMGB1, as an SI molecule, plays an important role in the development of thrombosis.

Neutrophil activation associated with the production of antibacterial peptides, reactive oxygen intermediates, cytokines, and other inflammatory mediators, as well as the release of DNA into the extracellular milieu, plays a central role in innate host defense and the modulation of inflammation [74]. NETs are produced through the release of DNA by neutrophils [74]. They are also formed in response to proinflammatory stimuli, including LPS, IL-8, and TNF- $\alpha$, as well as through enhanced generation 
of ROS by NADPH oxidase [74]. Tadie et al. [75] demonstrated that exposure of neutrophils to HMGB1 resulted in NETosis in vitro. They also showed that HMGB1-induced NETosis is mediated by TLR-4, which is consistent with previous studies that demonstrated that TLR-4 engagement enhances extracellular DNA release and the generation of NETs [75]. The TLR-4-MyD88 signaling pathway is mainly involved in NETosis through the release of DNA [76]. However, recent studies have shown that other signaling events, including the activation of NADPH oxidase or the stimulation of TLR-2, can also promote NETosis [77].

NETs contribute to venous thrombosis [78], DIC [79], and coronary thrombosis $[80,81]$. NETs may also provide a milieu for $\mathrm{vWF}$ to facilitate the adhesion of platelets through surface receptors and lead to platelet activation [82]. The extracellular histones also facilitate platelet activation via the TLR-2 and TLR-4 pathways [83].

NETs stimulate both the extrinsic and intrinsic coagulation pathway [84]. Neutrophil elastase is known to cleave tissue-factor pathway inhibitor (TFPI) and enhance Factor Xa activity [85]. NETs contain neutrophil elastase which binds to TFPI and thereby facilitates the proteolytic inactivation of TFPI [86]. NETs also bind to Factor XII and stimulate fibrin formation via the intrinsic coagulation pathway [84].

Reduced NADPH is essential for biosynthetic reactions and antioxidant function through the generation of ROS [87]. ROS released by the NADPH oxidase complex can activate granular proteases and induce NETosis [88]. $\mathrm{NADPH}$ is also involved in HMGB1-induced activation of neutrophils [89, 90]. HMGB1 exert its effects on NETosis through TLR-2, TLR-4, and RAGE, which are dependent on NADPH oxidase [89]. Furthermore, TLR4-dependent activation of NADPH oxidase is mediated via the MyD88-IL-1 receptor-associated kinase (IRAK)(p38 mitogen activated protein kinase (p38 MAPK)/Akt signaling pathway [91].

\section{HMGB1, Coagulation, and Fibrinolysis}

Tissue factor (TF), also known as coagulation factor III, has been found to be involved in inflammation-related thrombosis [92]. HMGB1 can upregulate the expression of TF in monocytes [93]. HMGB1 also induces the expression and activation of TF in endothelial cells in a concentration- and time-dependent manner [93]. Its effect on TF activity induced by HMGB1 is partly attenuated by 3 neutralizing antibodies (anti-TLR-2, anti-TLR-4, and antiRAGE) and NF- $\kappa \mathrm{B} /$ early growth response- 1 (Egr-1) interference, suggesting that the TLR-2/TLR-4/RAGE and
NF- $\kappa \mathrm{B} /$ Egr-1 pathway mediates the HMGB1-induced expression of TF [93]. HMGB1 also induces the formation of the plasminogen activator inhibitor-1/tissue plasminogen activator (PAI-1/tPA) complexes, suggesting that it might prevent fibrinolysis via increased PAI-tPA complexes in endothelial cells [94]. Collectively, these data provide evidence that coagulation and fibrinolysis factors are involved in HMGB1-induced thrombosis.

Nitric oxide (NO), a second-messenger molecule has been shown to inhibit platelet aggregation and thrombosis $[95,96]$. During stress, HMGB1 is upregulated, which subsequently inhibits insulin-induced NO production [26]. In respiratory diseases such as chronic pulmonary disease (CPD) or obstructive sleep apnea (OSA), or in hypoxia, HMGB1 and vWF are unregulated and lead to the inhibition of NO production via the TLR-2-SP1-vWF pathway $[97,98]$. HMGB1, as an endogenous ligand is released in the plasma due to hypoxic stress and thus inhibits NO production via the upregulation of vWF. HMGB1 also downregulates endothelial NO synthase activity in coronary endothelial cells through endothelial dysfunction [99].

\section{The Role of HMGB1 in Hypertension}

Recently, several studies showed that HMGB1 also plays a role in hypertension. Dange et al. [100] showed that hypertensive rats were found to have significantly increased levels of HMGB 1 in the paraventricular nucleus of the hypothalamus as well as in the circulation. TLR-4 plays a role in hypertension, possibly via HMGB1. They also showed that the pathogenesis of hypertension is increased by the binding of HMGB1 to its specific receptors [100]. Nakamura et al. [101] showed a direct correlation of soluble RAGE and RAGE ligands like circulating HMGB1 in hypertensive patients, and recently, another study showed a direct relationship between HMGB1 and pulmonary hypertension [102].

\section{The Role of HMGB1 in Preeclampsia}

Preeclampsia (PE) is mainly developed due to reduced uteroplacental blood flow which causes the development of placental ischemia with oxidative stress, inflammation, necrosis, and structural damage [103]. Hypoxia and reduced nutrient supply are linked to exaggerated trophoblast cell necrosis [104]. These trophoblastic cells are rich sources of numerous alarmins such as uric acid, cell-free fetal DNA, HMGB1, and IL-1 $\alpha$; when they die, they release these alarmins into the extracellular environment which can result in a sterile inflammatory response [105]. 
HMGB1 is expressed by trophoblasts and can be found in either in their nucleus or cytoplasm [106]. Circulating levels of HMGB1 are increased in many inflammationrelated diseases including PE [5]. Placentae exposed to aPL or PE sera are increased in the amount of cytoplasmic HMGB1 in the syncytiotrophoblast [5].

Pradervand et al. [107] showed that circulating levels of HMGB1 are higher in third-trimester PE than in normal pregnancies. This evidence suggests that HMGB1 plays a role in the development of PE.

\section{HMGB1, an Innate Alarmin, and Its Role in the Pathogenesis of IR}

It was recently rediscovered that HMGB1, an evolutionarily conserved chromosomal protein, acts as a "danger signal" (alarmin) to alert the innate immune system to trigger the host defense and/or tissue repair [32]. HMGB1 was initially found to be a DNA-binding protein that is present in almost all eukaryotic cells, where it stabilizes nucleosome formation and acts as a nuclear factor that enhances transcription [108]. Recently, HMGB1 secretion has been demonstrated in response to tissue damage, thus indicating a prototype of emerging DAMPs [21]. HMGB1 is also secreted by activated immune cells, including macrophages, dendritic cells, and natural killer cells in response to infection and inflammatory stimuli. It is now increasingly evident that HMGB1 plays a major role in several disease conditions such as atherosclerosis, diabetes, arthritis, sepsis, and cancer [109]. Once secreted, HMGB1 induces an inflammatory response by the transduction of cellular signals via its receptors, such as TLR-2, TLR-4, and RAGE. HMGB1 has been demonstrated to exert intracellular and extracellular functions by activating key oncogenic signaling pathways. Furthermore, HMGB1 also acquires or augments a proinflammatory effect via proinflammatory mediators such as LPS, IL-1, and DNA [110]. These observations indicate that HMGB1 is an essential mediator of organ damage; however, its precise role and mechanisms remain unknown. Studies have shown that high serum levels of HMGB1 contribute to the development of many inflammatory diseases and also diabetes [111]. Singh et al. [26] showed a direct relationship of the stress-induced upregulation of HMGB1 with IR, which is mediated through TLR2. They further showed that stress-induced HMGB1 inhibited insulin-induced NO production through the upregulation of vWF $[26,98]$. HMGB1 can signal through RAGE and TLRs to the NF- $\mathrm{kB}$ signaling pathway, and thus contributes to the inflammatory responses in type 2 diabetes mellitus [32]. Increased levels of HMGB1 have been reported in both diabetic patients and animal models [26, 112]. For all of the above, it is clear that HMGB1 plays a role in the genesis and pathophysiology of IR.

\section{Therapeutic Potential of HMGB1}

HMGB1 has been shown to play a significant role in the development of several diseases, particularly CVDs, $\mathrm{PE}$, and IR. Although there are no drugs that target HMGB1 in clinical practice, some anti-HMGB1 agents have been shown to inhibit the expression of HMGB1 in ischemic animal models, including glycyrrhizin [113], ethyl pyruvate (EP) [114], fluvastatin [115], berberine [116], and bleacein [117].

Glycyrrhizin, a glycoconjugated triterpene present in licorice root, exerts protective effects in various diseases, including IR, by suppressing HMGB1 [26]. It also inhibits HMGB1 secretion in the cerebrospinal fluid and serum after stroke, and thereby improves patients' outcomes [118]. Glycyrrhizin also alleviates the aggravation of infarct volume in middle cerebral artery occlusion models [119]. The infarct volume and release of HMGB1 from the cerebral cortex into the serum were attenuated by glycyrrhizin in a focal cerebral ischemia-reperfusion model [104].

$\mathrm{EP}$, a simple aliphatic ester of pyruvic acid, has been shown to have anti-inflammatory effects and confer protective effects in various pathological conditions [120]. EP reduced circulating levels of HMGB1 and significantly prevented lethality [121]. Aspirin, a classical antiplatelet drug, significantly blocked thrombin- and collageninduced HMGB1 release in active platelets [122]. Two other antiplatelet drugs (clopidogrel and cilostazol) also attenuated the expression of HMGB1 in septic shock [123]. Thus, HMGB1 might serve as a novel target for antiplatelet drugs in thrombotic diseases.

Low-molecular-weight heparin (LMWH) decreased the expression of HMGB1 in inflammation [124]. LMWH was shown to suppress HMGB1 and NETosis, thus suggesting that it might exert a anticoagulant effect by regulating HMGB1-mediated NETosis [125]. In addition, 2-O, 3-O desulfated heparin inhibited HMGB1/RAGEmediated airway inflammation [126]. In macrophages, 2-O, 3-O desulfated heparin blocked HMGB1 secretion via the inhibition of the activity of acetyltransferase p300 [127]. Thus, HMGB1 might also be a new target for heparin during inflammation and thrombosis.

Similar to heparin, thrombomodulin is another potential drug for DIC. It exhibits its anti-inflammatory effect 
by regulating HMGB1. Recombinant soluble thrombomodulin ameliorated cerebral ischemic injury via an HMGB1 inhibitory mechanism in mice with middle cerebral artery occlusion and rats with cerebral vein sinus thrombosis $[64,94]$. In a rat model of sepsis, recombinant thrombomodulin suppressed thrombus formation and HMGB1 levels. Moreover, high-dose thrombomodulin tended to increase the bleeding events [128], suggesting that HMGB1 is a target for the antithrombotic effect of thrombomodulin. As vascular endothelial cells are critical in the antithrombotic effect, Bongoni et al. [94] explored the role of thrombomodulin in HMGB1-induced endothelial cell activation. The authors further demonstrated that transgenic expression of thrombomodulin inhibited the activation of endothelial cells via increased HMGB1-induced cleavage [129]. Combining these findings, HMGB1 can be considered to serve as a potential target for the control of CVDs.

\section{Conclusions}

HMGB1 and other SI molecules can be actively or passively released from several cells during stress, including hypoxia. Once released into the extracellular space,
HMGB1 activates downstream signaling pathway by interacting with its receptors. Elevated levels of HMGB1 are associated with a poor clinical prognosis and outcome in several diseases including CVDs, IR, PE, etc. Currently, drugs are available that specifically target HMGB1. Therefore, the discovery and availability of a novel low-molecular-weight drug or compound will markedly improve the future therapeutic treatment and outcome of CVDs.

\section{Acknowledgement}

I express my sincere gratitude to my late mentor Prof. Asru K. Sinha, DSc. for inspiring guidance.

\section{Disclosure Statement}

The authors have no conflicts of interest to disclose.

\section{Funding Sources}

This work was supported by grants from the Grand Challenges Canada (R-ST-POC-1807-13914) to G.A.K.

\section{References}

1 Nadeau-Vallée M, Obari D, Palacios J, Brien ME, Duval C, Chemtob S, Girard S: Sterile inflammation and pregnancy complications: a review. Reproduction 2016;152:277-292.

2 Boonyaratanakornkit V, Melvin V, Prendergast $\mathrm{P}$, Altmann M, Ronfani L, Bianchi ME, et al: High-mobility group chromatin proteins 1 and 2 functionally interact with steroid hormone receptors to enhance their DNA binding in vitro and transcriptional activity in mammalian cells. Mol Cell Biol 1998;18: 4471-4487.

3 Erlandsson Harris H, Andersson U: Mini-review: the nuclear protein HMGB1 as a proinflammatory mediator. Eur J Immunol 2004; 34:1503-1512.

4 Harris HE, Andersson U, Pisetsky DS: HMGB1: a multifunctional alarmin driving autoimmune and inflammatory disease. Nat Rev Rheumatol 2012;8:195-202.

5 Tsung A, Tohme S, Billiar TR: High-mobility group box- 1 in sterile inflammation. J Intern Med 2014;276:425-443.

6 Scaffidi P, Misteli T, Bianchi ME: Release of chromatin protein HMGB1 by necrotic cells triggers inflammation. Nature 2002;418:191195.
7 Venereau E, Schiraldi M, Uguccioni M, Bianchi ME: HMGB1 and leukocyte migration during trauma and sterile inflammation. Mol Immunol 2013;55:76-82.

8 Magna M, Pisetsky DS: The role of HMGB1 in the pathogenesis of inflammatory and autoimmune diseases. Mol Med 2014;20:138146.

9 Yanai H, Matsuda A, An J, Koshiba R, Nishio J, Negishi $\mathrm{H}$, et al: Conditional ablation of HMGB1 in mice reveals its protective function against endotoxemia and bacterial infection. PNAS 2013;110:20699-20704.

10 Antoine DJ, Harris HE, Andersson U, Tracey KJ, Bianchi ME: A systematic nomenclature for the redox states of high mobility group box (HMGB) proteins. Mol Med 2014;20:135137.

11 Schiraldi M, Raucci A, Munoz LM, Livoti E, Celona B, Venereau E, et al: HMGB1 promotes recruitment of inflammatory cells to damaged tissues by forming a complex with CXCL12 and signaling via CXCR4. J Exp Med 2012;209:551-563.

12 Di Maggio S, Milano G, De Marchis F, D'Ambrosio A, Bertolotti M, Palacios BS, et al: Non-oxidizable HMGB1 induces car- diac fibroblasts migration via CXCR4 in a CXCL12-independent manner and worsens tissue remodeling after myocardial infarction. Biochim Biophys Acta 2017;1863:26932704.

13 Vogel S, Rath D, Borst O, Mack A, Loughran $\mathrm{P}$, Lotze MT, et al: Platelet-derived highmobility group box 1 promotes recruitment and suppresses apoptosis of monocytes. Biochem Biophys Res Commun 2016;478: 143-148.

14 Yang H, Antoine DJ, Andersson U, Tracey KJ: The many faces of HMGB1: molecular structure-functional activity in inflammation, apoptosis, and chemotaxis. J Leukoc Biol 2013;93:865-873.

15 Ma F, Kouzoukas DE, Meyer-Siegler KL, Westlund KN, Hunt DE, Vera PL: Disulfide high mobility group box-1 causes bladder pain through bladder Toll-like receptor 4 . BMC Physiol 2017;17:6.

16 Frank MG, Weber MD, Fonken LK, Hershman SA, Watkins LR, Maier SF: The redox state of the alarmin HMGB1 is a pivotal factor in neuroinflammatory and microglial priming: a role for the NLRP3 inflammasome. Brain Behav Immun 2016;55:215-224. 
17 Wu H, Sheng ZQ, Xie J, Li R, Chen L, Li GN, Wang L, Xu B: Reduced HMGB 1-mediated pathway and oxidative stress in resveratroltreated diabetic mice: a possible mechanism of cardioprotection of resveratrol in diabetes mellitus. Oxid Med Cell Longev 2016;2016: 9836860.

18 Wu H, Li R, Wei ZH, Zhang XL, Chen JZ, Dai $\mathrm{Q}$, et al: Diabetes-induced oxidative stress in endothelial progenitor cells may be sustained by a positive feedback loop involving high mobility group box-1. Oxid Med Cell Longev 2016;2016:1943918.

19 Stark K, Philippi V, Stockhausen S, Busse J, Antonelli A, Miller M, et al: Disulfide HMGB1 derived from platelets coordinates venous thrombosis in mice. Blood 2016;128:2435-2449.

20 Yang H, Lundback P, Ottosson L, Erlandsson-Harris H, Venereau E, Bianchi ME, et al: Redox modification of cysteine residues regulates the cytokine activity of high mobility group box-1 (HMGB1). Mol Med 2012;18: 250-259.

21 Lotze MT, Tracey KJ: High-mobility group box 1 protein (HMGB1): nuclear weapon in the immune arsenal. Nat Rev Immunol 2005; 5:331-342.

22 Walko TD III, Di Caro V, Piganelli J, Billiar TR, Clark RS, Aneja RK: Poly(ADP-ribose) polymerase 1-sirtuin 1 functional interplay regulates LPS-mediated high mobility group box 1 secretion. Mol Med 2015;20:612-624.

23 Cai J, Wen J, Bauer E, Zhong H, Yuan H, Chen AF: The role of HMGB1 in cardiovascular biology: danger signals. Antioxid Redox Signal 2015;23:1351-1369.

24 Harada S, Matsuura W, Liu K, Nishibori M, Tokuyama S: Possible involvement of the HMGB1/RAGE signaling mechanism in the induction of central post-stroke pain induced by acute global cerebral ischemia. Brain Res 2016;1646:433-440.

25 Soro-Paavonen A, Watson AM, Li J, Paavonen $\mathrm{K}$, Koitka A, Calkin AC, et al: Receptor for advanced glycation end products (RAGE) deficiency attenuates the development of atherosclerosis in diabetes. Diabetes 2008;57: 2461-2469.

26 Singh B, Biswas I, Bhagat S, Surya Kumari S, Khan GA: HMGB1 facilitates hypoxia-induced vWF upregulation through TLR2MYD88-SP1 pathway. Eur J Immunol 2016; 46:2388-2400.

27 Yao H, Hu C, Yin L, Tao X, Xu L, Qi Y, et al: Dioscin reduces lipopolysaccharide-induced inflammatory liver injury via regulating TLR4/MyD88 signal pathway. Int Immunopharmacol 2016;36:132-141.

28 Sumiyoshi M, Satomi J, Kitazato KT, Yagi K, Shimada K, Kurashiki Y, et al: PPAR $\gamma$ dependent and -independent inhibition of the HMGB1/TLR9 pathway by eicosapentaenoic acid attenuates ischemic brain damage in ovariectomized rats. J Stroke Cerebrovasc Dis 2015;24:1187-1195.

29 Hassanian S, Dinarvand P, Rezaie AR: Adenosine regulates the proinflammatory signal- ing function of thrombin in endothelial cells. J Cell Physiol 2014;229:1292-1300.

30 Mohammad G, Siddiquei MM, Othman A, Al-Shabrawey M, Abu El-Asrar AM: Highmobility group box-1 protein activates inflammatory signaling pathway components and disrupts retinal vascular-barrier in the diabetic retina. Exp Eye Res 2013;107:101109.

31 Xie HL, Zhang Y, Huang YZ, Li S, Wu CG, Jiao XF, et al: Regulation of high mobility group box 1 and hypoxia in the migration of mesenchymal stem cells. Cell Biol Int 2014;38: 892-897.

32 Kang R, Livesey KM, Zeh HJ, Loze MT, Tang D: HMGB1: a novel beclin 1-binding protein active in autophagy. Autophagy 2010;6:12091211.

33 Cui W, Li L, Li D, Mo X, Zhou W, Zhang Z, et al: Total glycosides of Yupingfeng protects against bleomycin-induced pulmonary fibrosis in rats associated with reduced high mobility group box 1 activation and epithelial-mesenchymal transition. Inflamm Res 2015;64: 953-961.

34 Li W, Ling HP, You WC, Ji XJ, Tang Y, Zhao $\mathrm{JB}$, et al: Recombinant high-mobility group box 1 protein (HMGB1) promotes myeloid differentiation primary response protein 88 (Myd88) upregulation in mouse primary cortical neurons. Neurol Sci 2013;34:847-853.

35 Kim S, Kim SY, Pribis JP, Lotze M, Mollen KP, Shapiro R, et al: Signaling of high mobility group box 1 (HMGB1) through toll-like receptor 4 in macrophages requires $\mathrm{CD} 14 . \mathrm{Mol}$ Med 2013;19:88-98.

36 Kaczorowski DJ, Nakao A, Vallabhaneni R, Mollen KP, Sugimoto R, Kohmoto J, et al: Mechanisms of Toll-like receptor 4 (TLR4)mediated inflammation after cold ischemia/ reperfusion in the heart. Transplantation 2009;87:1455-1463.

37 Wang C, Wang H, Chang DY, Hao J, Zhao $\mathrm{MH}$, Chen M: High mobility group box 1 contributes to anti-neutrophil cytoplasmic antibody-induced neutrophils activation through receptor for advanced glycation end products (RAGE) and Toll-like receptor 4. Arthritis Res Ther 2015;17:64.

38 Liu-Bryan R, Terkeltaub R: Chondrocyte innate immune myeloid differentiation factor 88 -dependent signaling drives procatabolic effects of the endogenous Toll-like receptor $2 /$ Toll-like receptor 4 ligands low molecular weight hyaluronan and high mobility group box chromosomal protein 1 in mice. Arthritis Rheumatol 2010;62:2004-2012.

39 Cheng Y, Wang D, Wang B, Li H, Xiong J, Xu $S$, et al: HMGB1 translocation and release mediate cigarette smoke-induced pulmonary inflammation in mice through a TLR4/MyD88dependent signaling pathway. Mol Biol Cell 2017;28:201-209.

40 Das N, Dewan V, Grace PM, Gunn RJ, Tamura R, Tzarum N, et al: HMGB1 activates proinflammatory signaling via TLR5 leading to allodynia. Cell Rep 2016;17:1128-1140.
41 Cirillo P, Giallauria F, Pacileo M, Petrillo G, D’Agostino M, Vigorito C, Chiariello M: Increased high mobility group box-1 protein levels are associated with impaired cardiopulmonary and echocardiographic findings after acute myocardial infarction. J Card Fail 2009; 15:362-367.

42 Goldstein RS, Gallowitsch-Puerta M, Yang L, Rosas-Ballina M, Huston JM, Czura CJ, et al: Elevated high-mobility group box 1 levels in patients with cerebral and myocardial ischemia. Shock 2006;25:571-574.

43 Su Z, Lu H, Jiang H, Zhu H, Li Z, Zhang P, et al: IFN- $\gamma$-producing Th17 cells bias by HMGB1-T- $\beta$ /RUNX3 axis might contribute to progression of coronary artery atherosclerosis. Atherosclerosis 2015;243:421-428.

44 Yamashita A, Nishihira K, Matsuura Y, Ito T, Kawahara K, Hatakeyama K, et al: Paucity of CD34-positive cells and increased expression of high-mobility group box 1 in coronary thrombus with type 2 diabetes mellitus. Atherosclerosis 2012;224:511-514.

$45 \mathrm{Hu}$ X, Jiang H, Bai Q, Zhou X, Xu C, Lu Z, et al: Increased serum HMGB1 is related to the severity of coronary artery stenosis. Clin Chim Acta 2009;406:139-142.

46 Andrassy M, Volz HC, Maack B, Schuessler A, Gitsioudis G, Hofmann N, et al: HMGB1 is associated with atherosclerotic plaque composition and burden in patients with stable coronary artery disease. PLoS One 2012;7:e52081.

47 Jin P, Zhou Q, Song S, Xu J, Zhang M, Zhu M, et al: Elevated preoperative HMGB1 as predictor of myocardial injury post-percutaneous coronary intervention. Medicine 2016;95:e5149.

48 Kohno T, Anzai T, Naito K, Miyasho T, Okamoto M, Yokota H, et al: Role of high-mobility group box 1 protein in post-infarction healing process and left ventricular remodelling. Cardiovasc Res 2009;81:565-573.

49 Schulze J, Zierath D, Tanzi P, Cain K, Shibata D, Dressel A, Becker K: Severe stroke induces long-lasting alterations of high-mobility group box 1. Stroke 2013;44:246-248.

50 Tang SC, Wang YC, Li YI, Lin HC, Manzanero S, Hsieh YH, et al: Functional role of soluble receptor for advanced glycation end products in stroke. Arterioscler Thromb Vasc Biol 2013;33:585-594.

51 Tsukagawa T, Katsumata R, Fujita M, Yasui K, Akhoon C, Ono K, et al: Elevated serum high-mobility group box-1 protein level is associated with poor functional outcome in ischemic stroke. J Stroke Cerebrovasc Dis 2017;26:2404-2411.

52 Lee JH, Yoon EJ, Seo J, Kavoussi A, Chung YE, Chung SP, et al: Hypothermia inhibits the propagation of acute ischemic injury by inhibiting HMGB1. Mol Brain 2016;9:81.

53 Nakamura Y, Nakano T, Irie K, Sano K, Tanaka J, Yamashita Y, et al: Recombinant human soluble thrombomodulin ameliorates cerebral ischemic injury through a high-mobility group box 1 inhibitory mechanism without hemorrhagic complications in mice. J Neurol Sci 2016;362:278-282. 
54 Chang CY, Kao TK, Chen WY, Ou YC, Li JR, Liao SL, et al: Tetramethylpyrazine inhibits neutrophil activation following permanent cerebral ischemia in rats. Biochem Biophys Res Commun 2015;463:421-427.

55 Zhang J, Takahashi HK, Liu K, Wake H, Liu $\mathrm{R}$, Maruo T, et al: Anti-high mobility group box-1 monoclonal antibody protects the blood-brain barrier from ischemia-induced disruption in rats. Stroke 2011;42:1420-1428.

56 Umahara T, Uchihara T, Hirokawa K, Hirao K, Shimizu S, Hashimoto T, et al: Time-dependent and lesion-dependent HMGB1-selective localization in brains of patients with cerebrovascular diseases. Histol Histopathol 2018;33:215-222.

57 Oozawa S, Sano S, Nishibori M: Usefulness of high mobility group box 1 protein as a plasma biomarker in patient with peripheral artery disease. Acta Med Okayama 2014;68:157162.

58 Giovannini S, Tinelli G, Biscetti F, Straface G, Angelini F, Pitocco D, et al: Serum high mobility group box-1 and osteoprotegerin levels are associated with peripheral arterial disease and critical limb ischemia in type 2 diabetic subjects. Cardiovasc Diabetol 2017;16:99.

59 Tsao CF, Huang WT, Liu TT, Wang PW, Liou CW, Lin TK, et al: Expression of high-mobility group box protein 1 in diabetic foot atherogenesis. Genet Mol Res 2015;14:45214531.

60 Wang M, Mei H, Kou H, Deng J, Wang H, Guo T, Hu Y: Role of plasma high mobility group box-1 in disseminated intravascular coagulation with leukemia. Thromb Res 2015; 136:422-426.

61 Hatada T, Wada H, Nobori T, Okabayashi K, Maruyama K, Abe Y, et al: Plasma concentrations and importance of high mobility group box protein in the prognosis of organ failure in patients with disseminated intravascular coagulation. Thromb Haemost 2005;94:975979 .

62 Inoue Y, Saito T, Ogawa K, Nishio Y, Kosugi S, Suzuki Y, et al: Role of serum high mobility group box 1 in hematological malignancies complicated with systemic inflammatory response syndrome and effect of recombinant thrombomodulin. Leuk Lymphoma 2013;54: 1953-1958.

63 Nomura S, Fujita S, Ozasa R, Nakanishi T, Miyaji M, Mori S, et al: The correlation between platelet activation markers and HMGB1 in patients with disseminated intravascular coagulation and hematologic malignancy. Platelets 2011;22:396-397.

$64 \mathrm{Gu} J J$, Chen JB, Zhang JH, Zhang H, Wang SS: Recombinant human soluble thrombomodulin protects against brain injury in a CVST rat model, via downregulation of the HMGB1RAGE axis. Mol Med Rep 2016;14:52175222.

65 Rouhiainen A, Imai S, Rauvala H, Parkkinen $\mathrm{J}$ : Occurrence of amphoterin (HMG1) as an endogenous protein of human platelets that is exported to the cell surface upon platelet activation. J Thromb Haemost 2000;84:10871094.

66 Maugeri N, Campana L, Gavina M, Covino C, De Metrio M, Panciroli C, et al: Activated platelets present high mobility group box 1 to neutrophils, inducing autophagy and promoting the extrusion of neutrophil extracellular traps. J Thromb Haemost 2014;12:20742088.

67 Ito T, Kawahara K, Nakamura T, Yamada S, Nakamura T, Abeyama K, et al: High-mobility group box 1 protein promotes development of microvascular thrombosis in rats. J Thromb Haemost 2007;5:109-116.

68 Yang X, Wang H, Zhang M, Liu J, Lv B, Chen F: HMGB1: a novel protein that induced platelets active and aggregation via Toll-like receptor-4, NF- $\mathrm{kB}$ and cGMP dependent mechanisms. Diagn Pathol 2015;10:134.

69 Vogel S, Bodenstein R, Chen Q, Feil S, Feil R, Rheinlaender J, et al: Platelet-derived HMGB1 is a critical mediator of thrombosis. J Clin Invest 2015;125:4638-4654.

70 Zhang G, Han J, Welch EJ, Ye RD, VoynoYasenetskaya TA, Malik AB, et al: Lipopolysaccharide stimulates platelet secretion and potentiates platelet aggregation via TLR4/ MyD88 and the cGMP-dependent protein kinase pathway. J Immunol 2009;182:79978004.

71 Yu LX, Yan L, Yang W, Wu FQ, Ling Y, Chen SZ, et al: Platelets promote tumour metastasis via interaction between TLR4 and tumour cell-released high-mobility group box1 protein. Nat Commun 2014;5:5256.

72 Rivadeneyra L, Carestia A, Etulain J, Pozner RG, Fondevila C, Negrotto S, Schattner M: Regulation of platelet responses triggered by Toll-like receptor 2 and 4 ligands is another non-genomic role of nuclear factor- $\mathrm{kB}$ Thromb Res 2014; 133:235-243.

73 Huebener P, Pradere JP, Hernandez C, Gwak GY, Caviglia JM, Mu X, et al: The HMGB1/ RAGE axis triggers neutrophil-mediated injury amplification following necrosis. J Clin Invest 2015; 125:539-550.

74 Brinkmann V, Reichard U, Goosmann C, Fauler B, Uhlemann Y, Weiss DS, et al: Neutrophil extracellular traps kill bacteria. Science 2004;303:1532-1535.

75 Tadie JM, Bae HB, Jiang S, Park DW, Bell CP, Yang $\mathrm{H}$, et al: HMGB1 promotes neutrophil extracellular trap formation through interactions with Toll-like receptor 4. Am J Physiol Lung Cell Mol Physiol 2013;304:342-349.

76 Juneau RA, Pang B, Weimer KE, Armbruster CE, Swords WE: Nontypeable Haemophilus influenzae initiates formation of neutrophil extracellular traps. Infect Immun 2011;79: 431-438.

77 Urbonaviciute V, Voll RE: High-mobility group box 1 represents a potential marker of disease activity and novel therapeutic target in systemic lupus erythematosus. J Intern Med 2011;270:309-318.

78 Martinod K, Demers M, Fuchs TA, Wong SL, Brill A, Gallant M, et al: Neutrophil histone modification by peptidylarginine deiminase 4 is critical for deep vein thrombosis in mice. PNAS 2013;110:8674-8679.

79 Delabranche X, Stiel L, Severac F, Galoisy AC, Mauvieux L, Zobairi F, et al: Evidence of netosis in septic shock-induced disseminated intravascular coagulation. Shock 2017;47: 313-317.

80 Riegger J, Byrne RA, Joner M, Chandraratne S, Gershlick AH, Ten Berg JM, et al: Histopathological evaluation of thrombus in patients presenting with stent thrombosis. A multicenter European study: a report of the prevention of late stent thrombosis by an interdisciplinary global European effort consortium. Eur Heart J 2016;37:1538-1549.

81 Mangold A, Alias S, Scherz T, Hofbauer T, Jakowitsch J, Panzenbock A, et al: Coronary neutrophil extracellular trap burden and deoxyribonuclease activity in ST-elevation acute coronary syndrome are predictors of ST-segment resolution and infarct size. Circ Res 2015;116:1182-1192.

82 Carestia A, Kaufman T, Schattner M: Platelets: New bricks in the building of neutrophil extracellular traps. Front Immunol 2016; 271

83 Semeraro F, Ammollo CT, Morrissey JH, Dale GL, Friese P, Esmon NL, Esmon CT: Extracellular histones promote thrombin generation through platelet-dependent mechanisms: involvement of platelet TLR2 and TLR4. Blood 2011;118:1952-1961.

84 von Bruhl ML, Stark K, Steinhart A, Chandraratne S, Konrad I, Lorenz M, et al: Monocytes, neutrophils, and platelets cooperate to initiate and propagate venous thrombosis in mice in vivo. J Exp Med 2012;209:819-835.

85 Higuchi DA, Wun TC, Likert KM, Broze GJ Jr: The effect of leukocyte elastase on tissue factor pathway inhibitor. Blood 1992;79: 1712-1719.

86 Massberg S, Grahl L, von Bruehl ML, Manukyan D, Pfeiler S, Goosmann C, et al: Reciprocal coupling of coagulation and innate immunity via neutrophil serine proteases. Nat Med 2010;16:887-896.

87 Fuchs TA, Brill A, Wagner DD: Neutrophil extracellular trap (NET) impact on deep vein thrombosis. Arterioscler Thromb Vasc Biol 2012;32:1777-1783.

88 Nguyen GT, Green ER, Mecsas J: Neutrophils to the ROScue: mechanisms of NADPH oxidase activation and bacterial resistance. Front Cell Infect Microbiol 2017;7:373.

$89 \mathrm{Ma}$ YH, Ma TT, Wang C, Wang H, Chang DY, Chen M, Zhao MH: High-mobility group box 1 potentiates antineutrophil cytoplasmic antibody-inducing neutrophil extracellular traps formation. Arthritis Res Ther 2016;18:2.

90 Xiang M, Yin L, Li Y, Xiao G, Vodovotz Y, Billiar TR, et al: Hemorrhagic shock activates lung endothelial reduced nicotinamide adenine dinucleotide phosphate (NADPH) oxidase via neutrophil NADPH oxidase. Am J Respir Cell Mol Biol 2011;44: 333-340. 
91 Fan J, Li Y, Levy RM, Fan JJ, Hackam DJ, Vodovotz Y, Yang H, et al: Hemorrhagic shock induces $\mathrm{NAD}(\mathrm{P}) \mathrm{H}$ oxidase activation in neutrophils: role of HMGB1-TLR4 signaling. J Immunol 2007;178:6573-6580.

92 Biswas I, Garg I, Singh B, Khan GA: A key role of toll-like receptor 3 in tissue factor activation through extracellular signal regulated kinase $1 / 2$ pathway in a murine hypoxia model. Blood Cells Mol Dis 2012;49:92-101.

93 Lv B, Wang H, Tang Y, Fan Z, Xiao X, Chen F: High-mobility group box 1 protein induces tissue factor expression in vascular endothelial cells via activation of NF- $\kappa B$ and Egr1. Thromb Haemost 2009;102:352-359.

94 Bongoni AK, Klymiuk N, Wolf E, Ayares D, Rieben R, Cowan PJ: transgenic expression of human thrombomodulin inhibits HMGB1induced porcine aortic endothelial cell activation. Transplantation 2016;100:1871-1879.

95 Chakraborty K, Khan GA, Banerjee P, Ray U, Sinha AK: Inhibition of human blood platelet aggregation and the stimulation of nitric oxide synthesis by aspirin. Platelets 2009; 14:421-427.

96 Loscalzo J: Nitric oxide insufficiency, platelet activation, and arterial thrombosis. Circ Res 2001;88:756-762.

$97 \mathrm{Wu}$ KM, Lin CC, Chiu CH, Liaw SF: Effect of treatment by nasal continuous positive airway pressure on serum high mobility group box-1 protein in obstructive sleep apnea. Chest 2010;137:303-309.

98 Singh B, Biswas I, Garg I, Sugadev R, Singh AK, Dey S, Khan GA: von Willebrand factor antagonizes nitric oxide synthase to promote insulin resistance during hypoxia. Biochemistry 2014;53:115-126.

99 Zhang Y, Li X, Pitzer AL, Chen Y, Wang L, Li PL: Coronary endothelial dysfunction induced by nucleotide oligomerization domainlike receptor protein with pyrin domain containing 3 inflammasome activation during hypercholesterolemia: beyond inflammation. Antioxid Redox Signal 2015;22:1084-1096.

100 Dange RB, Agarwal D, Teruyama R, Francis $\mathrm{J}$ : Toll-like receptor 4 inhibition within the paraventricular nucleus attenuates blood pressure and inflammatory response in a genetic model of hypertension. J Neuroinflamm 2015;12:31.

101 Nakamura K, Adachi H, Matsui T, Kurita Y, Takeuchi M, Yamagishi S: Independent determinants of soluble form of receptor for advanced glycation end products in elderly hypertensive patients. Metabolism 2009;58: 421-425.

102 Li WJ, Hu K, Yang JP, Xu XY, Li N, Wen ZP, Wang H: HMGB1 affects the development of pulmonary arterial hypertension via RAGE. Eur Rev Med Pharmacol Sci 2017;21: 3950-3958.

103 Huppertz B, Kingdom J, Caniggia I, Desoye G, Black S, Korr H, Kaufmann P: Hypoxia favours necrotic versus apoptotic shedding of placental syncytiotrophoblast into the maternal circulation. Placenta 2003;24:181-190.
104 Chen Q, Stone PR, McCowan LM, Chamley LW: Phagocytosis of necrotic but not apoptotic trophoblasts induces endothelial cell activation. Hypertension 2006;47:116-121.

105 Phillippe M: Cell-free fetal DNA - a trigger for parturition. N Engl J Med 2014;370: 2534-2536.

106 Shao J, Zhao M, Tong M, Wei J, Wise MR, Stone P, et al: Increased levels of HMGB1 in trophoblastic debris may contribute to preeclampsia. Reproduction 2016;152:775-784.

107 Pradervand PA, Clerc S, Frantz J, Rotaru C, Bardy D, Waeber B, et al: High mobility group box 1 protein (HMGB1): a pathogenic role in preeclampsia? Placenta 2014;35: 784-786.

108 Muller S, Ronfani L, Bianchi ME: Regulated expression and subcellular localization of HMGB1, a chromatin protein with a cytokine function. J Intern Med 2004;255:332-343.

109 Wang H, Bloom O, Zhang M, Vishnubhakat JM, Ombrellino M, Che J, et al: HMG-1 as a late mediator of endotoxin lethality in mice. Science 1999;285:248-251.

110 Urbonaviciute V, Furnrohr BG, Meister S, Munoz L, Heyder P, De Marchis F, et al: Induction of inflammatory and immune responses by HMGB1-nucleosome complexes: implications for the pathogenesis of SLE. J Exp Med 2008;205:3007-3018.

111 Dasu MR, Devaraj S, Park S, Jialal I: Increased toll-like receptor (TLR) activation and TLR ligands in recently diagnosed type 2 diabetic subjects. Diabetes Care 2010;33: 861-868.

112 Wang Y, Zhong J, Zhang X, Liu Z, Yang Y, Gong Q, Ren B: The Role of HMGB1 in the pathogenesis of type 2 diabetes. J Diabetes Res 2016;2016.

113 Gong G, Xiang L, Yuan L, Hu L, Wu W, Ai $\mathrm{L}$, et al: Protective effect of glycyrrhizin, a direct HMGB1 inhibitor, on focal cerebral ischemia/reperfusion-induced inflammation, oxidative stress, and apoptosis in rats. PLoS One 2014;9:e89450.

114 Xiao H, Liu H, Hou C, Liu Y, Yu Q: Effects of ethyl pyruvate in preventing the development of diet-induced atherosclerosis by blocking the HMGB1 expression in ApoEdeficient mice. J Cardiovasc Pharmacol 2016;67:299-304.

115 Haraba R, Suica VI, Uyy E, Ivan L, Antohe F: Hyperlipidemia stimulates the extracellular release of the nuclear high mobility group box 1 protein. Cell Tissue Res 2011;346:361368.

116 Zhang T, Yang S, Du J: Protective effects of berberine on isoproterenol-induced acute myocardial ischemia in rats through regulating HMGB1-TLR4 axis. Evid Based Complement Alternat Med 2014;2014:849783.

117 Filipek A, Czerwinska ME, Kiss AK, Polanski JA, Naruszewicz M: Oleacein may inhibit destabilization of carotid plaques from hypertensive patients. Impact on high mobility group protein-1. Phytomedicine 2017;32: 68-73.
118 Xiong X, Gu L, Wang Y, Luo Y, Zhang H, Lee $\mathrm{J}$, et al: Glycyrrhizin protects against focal cerebral ischemia via inhibition of $\mathrm{T}$ cell activity and HMGB1-mediated mechanisms. J Neuroinflamm 2016;13:241.

119 Huang J, Liu B, Yang C, Chen H, Eunice D, Yuan Z: Acute hyperglycemia worsens ischemic stroke-induced brain damage via high mobility group box-1 in rats. Brain Res 2013 1535:148-155.

120 Shin JH, Kim ID, Kim SW, Lee HK, Jin Y, Park JH, et al: Ethyl pyruvate inhibits HMGB1 phosphorylation and release by chelating calcium. Mol Med 2015;20:649657.

121 Dave SH, Tilstra JS, Matsuoka K, Li F, DeMarco RA, Beer-Stolz D, et al: Ethyl pyruvate decreases HMGB1 release and ameliorates murine colitis. J Leukoc Biol 2009;86: 633-643.

122 Goetzl EJ, Goetzl L, Karliner JS, Tang N, Pulliam L: Human plasma platelet-derived exosomes: effects of aspirin. FASEB J 2016;30: 2058-2063.

123 Hagiwara S, Iwasaka H, Hasegawa A, Oyama M, Imatomi R, Uchida T, Noguchi T: Adenosine diphosphate receptor antagonist clopidogrel sulfate attenuates LPS-induced systemic inflammation in a rat model. Shock 2011;35:289-292.

124 Ning F, Wang X, Shang L, Wang T, Lv C, Q $\mathrm{Z}$, Wu D: Low molecular weight heparin may prevent acute lung injury induced by sepsis in rats. Gene 2015;557:88-91.

125 Manfredi AA, Rovere-Querini P, D’Angelo A, Maugeri N: Low molecular weight heparins prevent the induction of autophagy of activated neutrophils and the formation of neutrophil extracellular traps. Pharmacol Res 2017;123:146-156.

126 Rao NV, Argyle B, Xu X, Reynolds PR, Walenga JM, Prechel $M$, et al: Low anticoagulant heparin targets multiple sites of inflammation, suppresses heparin-induced thrombocytopenia, and inhibits interaction of RAGE with its ligands. Am J Physiol Cell Physiol 2010;299:97-110.

127 Zheng S, Kummarapurugu AB, Afosah DK Sankaranarayanan NV, Boothello RS, Desai UR, et al: 2-O, 3-O desulfated heparin blocks high mobility group box 1 release by inhibition of p300 acetyltransferase activity. Am J Respir Cell Mol Biol 2017;56:90-98.

128 Iba T, Aihara K, Watanabe S, Yanagawa Y, Takemoto M, Yamada A, Yang D: Recombinant thrombomodulin improves the visceral microcirculation by attenuating the leukocyte-endothelial interaction in a rat LPS model. Thromb Res 2013;131:295-299.

129 Ito T, Kawahara K, Okamoto K, Yamada S, Yasuda M, Imaizumi H, et al: Proteolytic cleavage of high mobility group box 1 protein by thrombin-thrombomodulin complexes. Arterioscler Thromb Vasc Biol 2008; 28:1825-1830. 